\title{
THE PAST AND FUTURE OF GLOBAL MOBILITY
}

\author{
Andreas Schäfer \\ Massachusetts Institute of Technology \\ Cambridge, MA, USA \\ David Victor \\ International Institute for Applied Systems Analysis \\ Laxenburg, Austria
}

RR- $97-13$

November 1997

Reprinted from Scientific American,

October 1997.

International Institute for Applied Systems Analysis, Laxenburg, Austria

Tel: +432236 807 Fax: +43223673148 E-mail: publications@iiasa.ac.at 
Research Reports, which record research conducted at IIASA, are independently reviewed before publication. Views or opinions expressed herein do not necessarily represent those of the Institute, its National Member Organizations, or other organizations supporting the work.

Reprinted with permission.

Copyright (c) 1997 by Scientific American, Inc.

All rights reserved.

All rights reserved. No part of this publication may be reproduced or transmitted in any form or by any means, electronic or mechanical, including photocopy, recording, or any information storage or retrieval system, without permission in writing from the copyright holder. 


\section{The Past and Future of Global Mobility}

\section{With growing wealth, people everywhere travel farther and faster. That trend inevitably brings a shift in the dominant transportation technologies}

by Andreas Schafer and David Victor

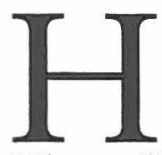

ow much will people travel in the future? Which modes of transport will they use? Where will traffic be most intense? The answers are critical for planning infrastructures and for assessing the consequences of mobility. They will help societies anticipate environmental problems such as regional acid rain and global warming, which are partially caused by transport emissions. These questions also lie at the center of efforts to estimate the future size of markets for transportation hardware-aircraft, automobiles, buses and trains.

In our research, we have tried to answer these questions for 11 geographic regions specifically and more generally for the world. One of us (Schafer) compiled historical statistics for all four of the principal motorized modes of transportation-trains, buses, automobiles and high-speed transport (aircraft and high-speed trains, which we place in a single category because both could eventually offer mobility at comparable quality and speed). Together we used that unique database to compose a scenario for the future volume of passenger trav$\mathrm{el}$, as well as the relative prevalence of different forms of transportation through the year 2050. Our perspective was both long term and large scale because trans- 
port infrastructures evolve slowly, and the effects of mobility are increasingly global. The answers to those fundamental questions, we found, depend largely on only a few factors.

Historical data suggest that, throughout the world, personal income and traffic volume grow in tandem. As average income increases, the annual distance traveled per capita by car, bus, train or aircraft (termed motorized mobility, or traffic volume) rises by roughly the same proportion. The average North American earned $\$ 9,600$ and traveled 12,000 kilometers $(7,460$ miles) in 1960 ; by 1990 both per capita income and traffic volume had approximately doubled.

In developing countries the relation has been less tight. Between 1960 and 1990 the average income in China tripled, but motorized traffic volume rose 10 -fold, to 630 kilometers. This discrepancy reflects, in part, the fact that growing wealth allows the poor to substitute motorized mobility, typically by bus or train, for nonmotorized forms such as walking and biking, for which the statistics are notoriously unreliable and so are excluded from our database.

The charted relation between income and traffic volume affirms a postulate by the late analyst Yacov Zahavi: on aver- age, humans devote a roughly predictable fraction of their expenditures to transportation. This fraction is typically 3 to 5 percent in developing countries, where people rely predominantly on nonmotorized and public transportation. The fraction rises with automobile ownership , stabilizing at 10 to 15 percent at ownership levels of 0.2 car per capita (one car per family of five). Nearly all members of the Organization for Economic Cooperation and Development (OECD) - the rich industrial nations-have completed this "automobile transition." Figures from the U.S., for example, show that this fraction remained nearly constant even during the two oil-price shocks of the 1970s; travelers compensated for higher operating costs by demanding less expensive (and more fuel-efficient) vehicles.

This predictable relation between income and transport spending allowed us to conjecture plausibly about the future. In the absence of major economic upsets, traffic volume should continue to rise with income, as in the past. Using reasonable assumptions for future income growth, we estimated that traffic volume in North America will rise to 58,000 passenger-kilometers a year in 2050. In China, annual motorized mo-

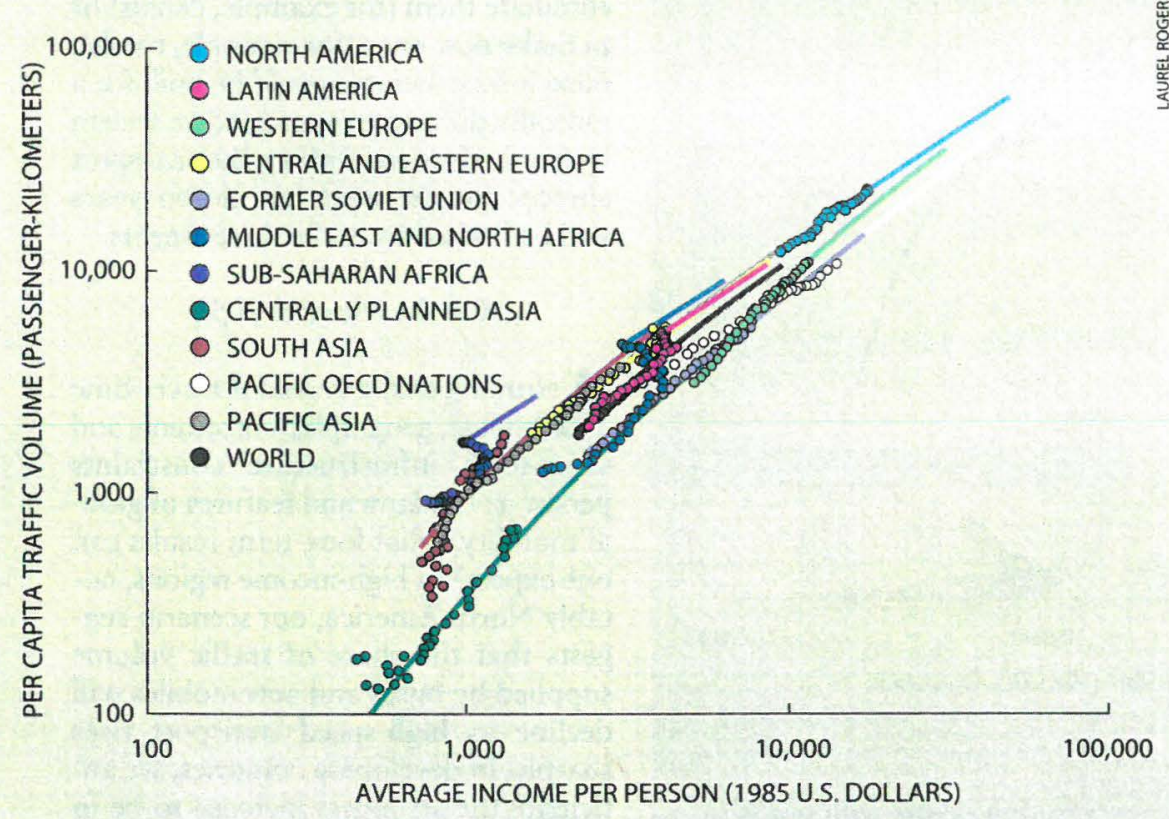

SOURCE: Andreas Schafer and David Victor

MOTORIZED TRANSPORTATION takes many forms around the world, ranging from relatively slow public transit through private automobiles to high-speed planes (opposite page). Data from 11 regions collected between 1960 and 1990 generally demonstrate that as income rises, societies become more mobile (above). All income data are weighted for differences in local prices. bility will reach 4,000 passenger-kilometers, which is comparable with western European levels in the mid-1960s. Developing countries will contribute a rising share to global traffic volume because, although their per capita mobility will stay lower, both their populations and their average incomes will grow faster than those of OECD nations. In 1960 the developing countries could claim only 22 percent of the world traffic volume, but by 2050 , we estimate, they will account for about half of it51 trillion passenger-kilometers.

\section{Higher Incomes, Higher Speeds}

$\mathrm{H}$ ow will people satisfy their growing demand for mobility? We searched for patterns in how modes of transportation compete. Again, Zahavi offered a useful starting point: he argued that people devote on average a constant fraction of their daily time to travelwhat he called the travel-time budget. All the reliable surveys that we have found support this hypothesis: the travel-time budget is typically between 1.0 and 1.5 hours per person per day in a wide variety of economic, social and geographic settings. Residents of African villages have a travel-time budget similar to those of Japan, Singapore, western Europe and North America. Small groups and individuals vary in their behavior, but at the level of aggregated populations, a person spends an average of 1.1 hours a day traveling.

If people hold their time for travel constant but also demand more mobility as their income rises, they must select faster modes of transport to cover more distance in the same time. Data from every region are consistent with that expectation. At low incomes (below $\$ 5,000$ per capita), motorized travel is dominated by buses and low-speed trains that, on average, move station-to-station at approximately 20 to 30 kilometers per hour. As income rises, slower public transport modes are replaced by automobiles, which typically operate doorto-door at 30 to $55 \mathrm{kph}$ and offer greater flexibility. (These average speeds, which vary by region, are lower than the posted speed limits because of congestion and other inefficiencies.) The share of traffic volume supplied by automobiles peaks at approximately $\$ 10,000$ per capita. At higher incomes, aircraft and high-speed trains supplant slower modes. At present, aircraft supply 96 percent of all high-speed transport, fly- 


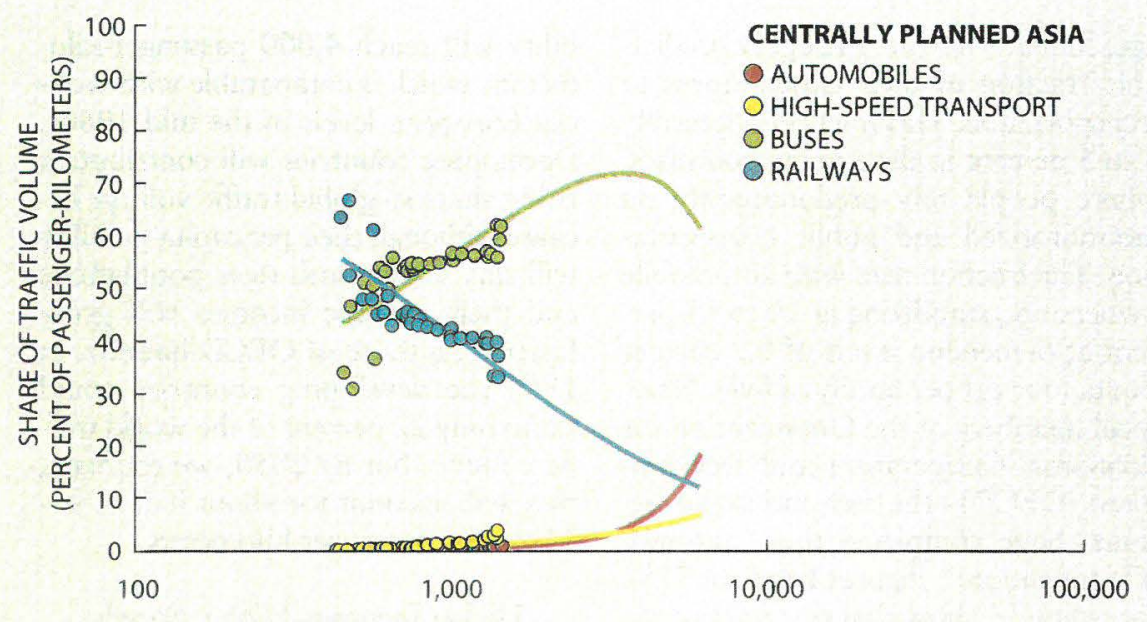

AVERAGE INCOME PER PERSON (1985 U.S. DOLLARS)
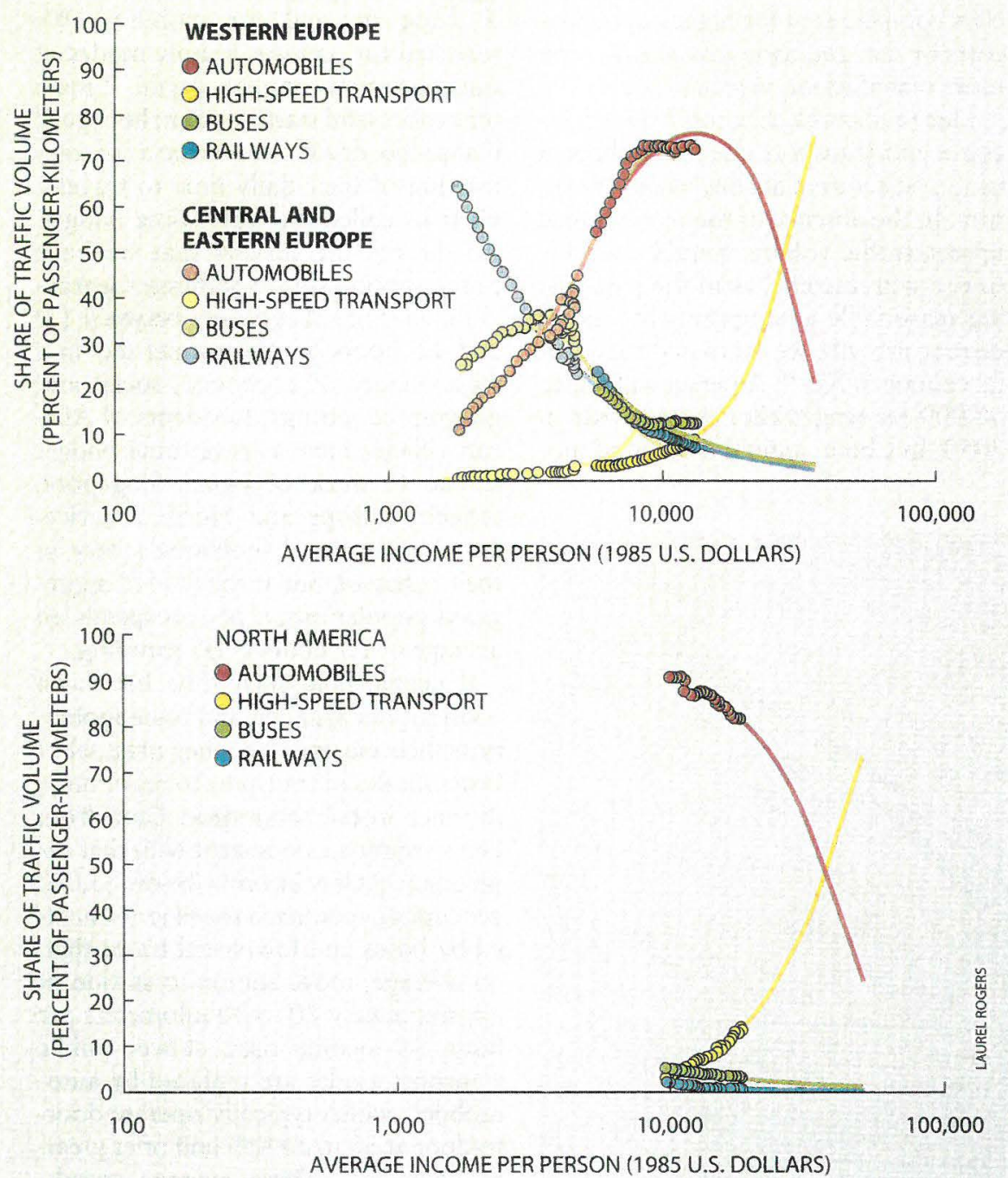

SOURCE: Andreas Schafer and David Victor

SHIFT FROM SLOW TO FAST MODES of transportation occurs with rise in income, as trends in several regions show. These curves represent historical data and future scenarios between 1960 and 2050. In centrally planned Asia (primarily China), buses are the preferred mode; trains are in decline, whereas cars and planes are of minor importance. In central and eastern Europe, cars are still on the rise, but in western Europe, a transition in favor of planes and high-speed trains is occurring. In North America, planes are already taking a share of traffic volume from cars. ing airport-to-airport at about $600 \mathrm{kph}$. Although the constancy of the traveltime budget pushes people with rising incomes toward faster modes of transportation, the share of motorized mobility that each mode holds is strongly determined by geography. In the late 1950 s, when Jack Kerouac extolled the open road in America, relatively few kilometers were motored by other means: by the 1960 s, private automobiles delivered 90 percent of North American traffic volume because the continent had plenty of space and plenty of roads. In contrast, in more densely populated western Europe, the share of automobiles never climbed so high-it has been stagnant at about 70 percent and is poised to decline. Asia is even more compact, with an urban density three times that of western Europe. Accordingly, we expect that automobiles will peak at only 55 percent of the total traffic volume in the high-income Pacific OECD nations, which is primarily attributable to Japan. Public transport will continue to account for a higher share of mobility in Asia than in less densely populated regions.

In addition, the availability of roads, rail beds, airports and other essential infrastructures constrains the transport choices. Because transport infrastructures are expensive and long-lived, it typically takes six to seven decades to eliminate them (for example, canals) or to make new ones (for example, roads). New infrastructures could be built for a radically different transportation system by late in the next century, but transport choices for the next few dozen years will be limited by earlier investments.

\section{On the Move in 2050}

ssuming that a constant travel-time A budget, geographic constraints and short-term infrastructure constraints persist as fundamental features of global mobility, what long-term results can one expect? In high-income regions, notably North America, our scenario suggests that the share of traffic volume supplied by buses and automobiles will decline as high-speed transport rises sharply. In developing countries, we anticipate the strongest increase to be in the shares first for buses and later for automobiles. Globally, these trends in bus and automobile transport are partially offsetting. From 1960 to 2050 the share of world traffic volume by buses will remain roughly constant, whereas

The Past and Future of Global Mobility 


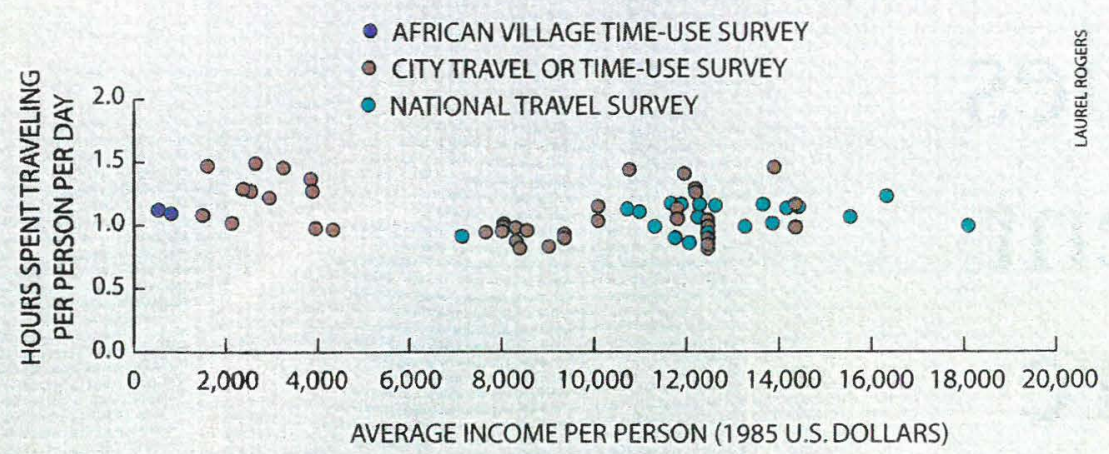

SOURCE: Andreas Schafer and David Victor

TRAVEL-TIME BUDGET, the amount of time that people devote to travel, is consistently about 1.1 hours per person a day in all societies, according to surveys.

the automobile share will decline only gradually to 35 percent. High-speed transport should account for about 40 percent of all passenger-kilometers traveled in 2050. In all regions, the share of low-speed rail transport will probably continue its strongly evident decline.

Despite the sharply rising share of air travel, other types of vehicles, including automobiles, will remain crucial parts of the transportation system. Even in North America, where we expect the relative decline of automobiles to be steepest, the absolute traffic volume supplied by cars will decline only after peaking at 22,000 passenger-kilometers per person in 2010. By 2050, automobiles will still supply 14,000 passenger-kilome- ters per person, which means that North Americans will be driving as much as they did in 1970 .

The allocation of travel time reflects the continuing importance of low-speed transport. We expect that throughout the period 1990-2050, the average North American will continue to devote most of his or her 1.1-hour travel-time budget to automobile travel. The very large demand for air travel (or highspeed rail travel) that will be manifest in 2050 works out to only 12 minutes per person a day; a little time goes a long way in the air. In several developing regions, most travel time in 2050 will still be devoted to nonmotorized modes. Buses will persist as the primary form of motorized transportation in developing countries for decades. No matter how important air travel becomes, buses, automobiles and even low-speed trains will surely go on serving vital niches. Some of the super-rich already commute and shop in aircraft, but average people will continue to spend most of their travel time on the ground.

WORLD TRAFFIC VOLUME, measured in passenger-kilometers (pkm), will continue to balloon, with higher-speed transport gaining market share. By 2050, automobiles will supply less than two fifths of global volume.

RAILWAYS

BUSES

AUTOMOBILES

HIGH-SPEED

TRANSPORT

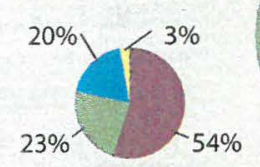

5.5 TRILLION PKM

1960

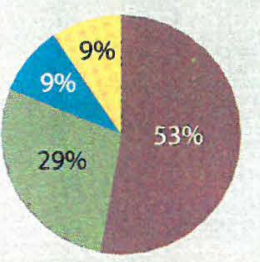

23.4 TRILLION PKM 1990

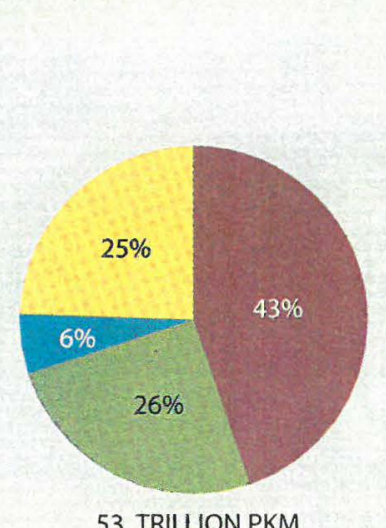

53 TRILLION PKM

2020

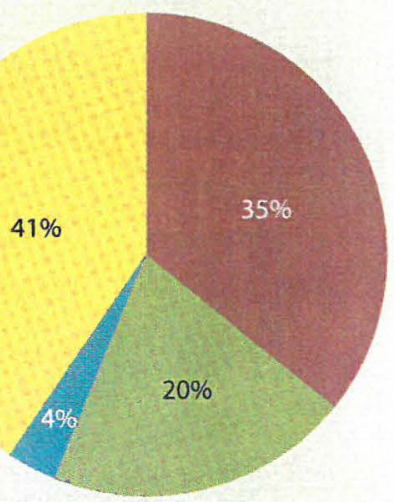

103 TRILLION PKM

2050

\section{The Authors}

ANDREAS SCHAFER and DAVID VICTOR collaborate on long-term and large-scale models of transportation. Schafer, an aeronautical engineer, works at the Massachusetts Institute of Technology Center for Technology, Policy and Industrial Development. He does systems analysis on transportation and global change in the Cooperative Mobility Program and the Joint Program on the Science and Policy of Global Change. Victor, a political scientist with the Environmentally Compatible Energy Strategies Project at the International Institute for Applied Systems Analysis (IIASA), focuses on energy technology and international environmental governance.

\section{Further Reading}

Personal Travel Budgets. Edited by H. R. Kirby. Special issue of Transportation Research, Part A (Pergamon Press, U.K.), Vol. 15, No. 1; January 1981.

The Evolution of Transport Systems: Past and Future. Arnulf Gruebler and Nebojsa Nakicenovic. Research Report RR-91-008, International Institute for Applied Systems Analysis, Laxenburg, Austria, 1991.

ANTHRopological INVARIANTS IN TRAVEL Behavior. C. Marchetti in Technological Forecasting and Social Change, Vol. 47, No. 1, pages 75-88; September 1994. The Future Mobility of the World Population. A. Schafer and D. G. Victor in The Cooperative Mobility Program. Discussion Paper 97-6-4, Center for Technology, Policy and Industrial Development, Massachusetts Institute of Technology, 1997.

The Global Demand for Motorized Mobility. Andreas Schafer in Transportation Research, Part A (in press). 
